\title{
VALUE PROPOSITION CANVAS APLICADO AO PROCESSO DE DESIGN: DESENVOLVIMENTO DE NOME E IDENTIDADE VISUAL PARA APLICATIVO DE MOBILIDADE EM CAMPUS UNIVERSITÁRIO
}

\author{
André Grilo \\ Fundação Norte-Rio-Grandense de Pesquisa e Cultura -UFRN \\ andregrilo@info.ufrn.br \\ Geraldo Neto \\ Fundação Norte-Rio-Grandense de Pesquisa e Cultura -UFRN \\ netto@info.ufrn.br \\ Laura Caroline Dias Fernandes \\ Fundação Norte-Rio-Grandense de Pesquisa e Cultura -UFRN \\ lauradias@info.ufrn.br
}

Resumo: Este artigo apresenta o processo de conceituação de nome e identidade visual para aplicativo de caronas desenvolvido em instituição pública de ensino superior, para uso exclusivo da comunidade acadêmica. São delineados a relevância do design de nomes (naming) na construção da marca e consolidação do produto, o contexto da mobilidade urbana e as novas tecnologias, as bases teóricas para o processo criativo adotado e a importância da empatia e do uso da ferramenta Value Proposition Canvas na construção da proposta de valor de marca e nome de um produto ou serviço, associando tal entendimento ao processo de definição de características desejadas e esperadas para o aplicativo. Os resultados indicaram uma proveitosa integração entre a subjetividade do público-alvo e objetividade da estratégia do produto.

Palavras-chave: Design, Metodologia, Mobilidade Urbana, Tecnologia da Informação.

Abstract: This paper shows the conceptualization process of naming and visual identity for a shared mobility mobile application, developed by a University for use only by the academic community. It were pointed the name design relevance in the construction and consolidation of the brand and its products, the issue about urban mobility and the new technologies, the theoretical basis of creative process adopted in this work and the importance of the empathy and the use of Value Proposition Canvas tool to define the expected attributes for the mobile application. The results shown proficient integration between subjectivity of people and objectivity of product strategy.

Keywords: Design, Methodology, Urban Mobility, Information Technology. 


\section{INTRODUÇÃO}

\subsection{Nome como atributo estratégico da identidade de marcas e produtos}

O conceito de identidade de uma marca é considerado na literatura um construto de ampla abrangência em uma organização e seus diversos pontos de contato, envolvendo muito mais do que os elementos visuais da marca, conforme Rodrigues (2011, p. 27): "Essa identidade de que se fala depende de fatores de mercado, do tipo de experiência que as pessoas têm com produtos ou com as atitudes das empresas e instituições". Ainda de acordo com o autor, a identidade de marca é constituída dos seguintes elementos:

- Posicionamento, que se refere à promessa e proposta de valor da marca;

- Identidade verbal, que engloba não apenas o nome (naming) da companhia ou serviço, mas também o tom de voz e linguagem que esta adota em sua comunicação com o público;

- Identidade visual, que define o caráter e crenças da empresa a partir de elementos gráficos padronizados, como símbolo, logotipo, uniformes, entre outros;

- Universo experiencial da identidade, composta por experiências sonoras, olfativas e táteis que ocorrem na interação com a marca.

No arcabouço da identidade de uma marca, o nome e o desenho gráfico da marca atuam em sinergia na entrega da promessa de experiência e proposta de valor da marca, sendo as partes tangíveis desta. O nome, no entanto, exercem ainda uma função institucional e jurídica, uma vez que ajuda a distinguir um serviço de outro similar e concorrente (RODRIGUES, 2011, p. 35-37). Assim, o nome de uma marca define substancialmente sua procedência e também a que públicos se destina, sendo necessária, para uma escolha adequada, uma atenta estratégia de mercado e conhecimento do nicho do produto ou serviço.

\subsection{Mobilidade urbana e as novas tecnologias}

A mobilidade urbana tem sido um tema frequentemente discutido, em face dos diversos problemas acarretados pelo acelerado e processo de crescimento urbano (MAGAGNIN e SILVA, 2008; BOARETO, 2008; RESENDE e SOUSA, 2009). Como resposta a tais problemáticas, surgem novos modelos de negócio no segmento, por vezes alicerçados em bases tecnológicas e viabilizados por meio de aplicativos móveis. Os casos mais emblemáticos nesse contexto que podem ser destacados são os aplicativos como o Uber, que permitem uma maior autonomia na experiência do usuário com o serviço de transporte particular. 


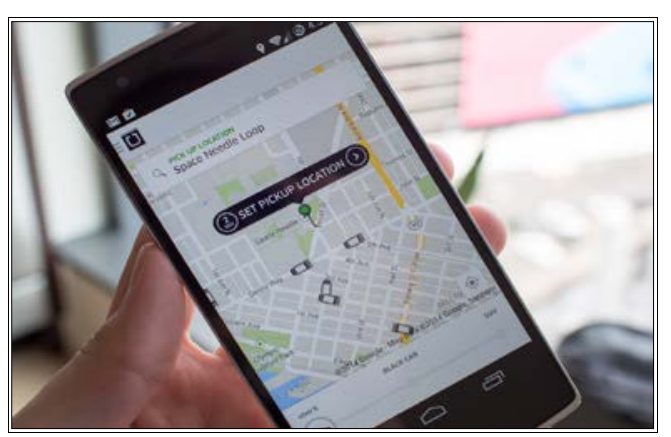

Figura 1 - Interface do aplicativo Uber.

Fonte: Disponível em <http://www.androidcentral.com/uber-opens-beta-program-those-who-wantnicer-and-possibly-less-stable-app-experience>. Acesso em maio 2016.

Referente ao termo experiência do usuário, é importante ressaltar que este se trata de um conceito abrangente, que contempla não somente produtos digitais, mas qualquer produção tecnológica industriada pelo homem (LOWDERMILK, 2013). Na visão de Norman (2010), porém, embora a sociedade tenha avançado a passos largos nas tecnologias inteligentes, falta às máquinas a empatia, qualidade esta que, segundo Queiroz (1999) é inerente ao seres humanos, e se refere à atitude de se colocar no lugar do semelhante, visualizando a situação na perspectiva do outro. Em outras palavras, as máquinas reproduzem aquilo para o qual foram programadas, porém é preciso dotá-las de uma abordagem mais orgânica e voltada para as diferentes maneiras como as pessoas se comportam, evitando fadá-las a um comportamento igualmente programado. Assim, da mesma forma que as pessoas possuem diferentes aspectos (físicos, cognitivos, sociais, culturais), se faz necessário olhar o produto nas mais diferentes perspectivas de seu prisma.

\subsection{0 usuário como direcionador do design do produto}

Tal preocupação com o projeto e concepção do produto é uma premissa básica da atuação do design. Embora comumente relacionado à estética e ao visual, o ofício do design surge no início do século XX com a visão de associar forma e função do objeto (ARGAN, 2005). Posteriormente, no período pós-guerras mundiais surge uma maior preocupação com a ergonomia usabilidade dos produtos (IIDA, 2005). Nos dias de hoje, tais princípios de design e usabilidade tem feito produtos como o Uber atingirem reconhecimento do seu público, pela adequação à realidade diária de seus utilizadores, e por permitirem uma maior autonomia, personalização e controle ao usuário (SHNEIDERMAN \& PLAISANT, 1986; NIELSEN, 1994) sobre o serviço que está sendo oferecido. Insere-se, nessa perspectiva, o conceito de design centrado no usuário, i.e., quando o produto é voltado para as necessidades, desejos e objetivos de seus utilizadores (LOWDERMILK, 2013).

Decorre desse entendimento que o produto não deve oferecer apenas uma contribuição tecnológica e econômica para os indivíduos, mas também deve contemplar questões culturais e sociais, aspectos indissociáveis na formação humana. Nesse sentido, as tecnologias devem levar em conta não apenas os aspectos técnicos e pragmáticos, mas a subjetividade de seus públicos, pois a maneira como interpretam o mundo e a realidade à sua volta influenciam a maneira como lidam com os produtos (SANTAELLA, 2005). No caso de aplicativos para mobilidade, ênfase deste trabalho, a 
percepção e subjetividade coletiva tornaram-se ingredientes importantes na constituição de características e recursos voltados para atender às necessidades dos grupos de interesse - sejam aqueles condutores que disponibilizam seus veículos, como aqueles que estão à procura de um meio para se deslocarem - posto que um produto de boa usabilidade deve ser pensado para auxiliar as pessoas em seus objetivos, necessidades e contextos específicos (INTERNATIONAL ORGANIZATION FOR STANDARDIZATION, 1998).

\section{ESTUDO DE CASO: NAMING PARA APLICATIVO DE CARONAS EM UNIVERSIDADE}

Desenvolveu-se, no setor de tecnologia da informação da Universidade Federal do Rio Grande do Norte (SINFO/UFRN), um aplicativo de mobilidade voltado para o incentivo a caronas, para uso exclusivo da comunidade acadêmica. A aplicação faz parte de uma ação promovida pela universidade, que viabiliza aos alunos, servidores docentes o uso de dados dos sistemas da instituição para o desenvolvimento de sistemas, aplicações e outros produtos tecnológicos de impacto na vida universitária e escaláveis para contextos além das fronteiras do campus. O projeto, intitulado "Api.sistemas", disponibiliza diversos dados na internet para uso exclusivo da comunidade acadêmica. De acordo com a página eletrônica oficial (2016, p. 1):

É uma interface de programação de aplicações (API) que tem como principal função disponibilizar os dados dos sistemas da UFRN e, assim, possibilitar que a comunidade acadêmica (alunos, professores e empresas) crie aplicações, em qualquer plataforma desejada, que necessitam desses dados para funcionar.

O objetivo da pesquisa foi desenvolver o conceito de um produto que estimulasse um comportamento solidário no contexto do campus universitário. Como objetivo específico, buscou-se investigar os valores esperados pelo público-alvo em relação ao tema, a fim de criar um nome, identidade visual e interface gráfica convidativos para os potenciais usuários. Para o processo de design do nome e marca do aplicativo, foram integradas abordagens de estratégia de negócios e semiótica, o primeiro servindo para considerar o aplicativo como um produto em busca de adesão de consumidores, os usuários; o segundo, para alinhar as estratégias às percepções e expectativas do público-alvo, equilibrando o lado objetivo com o subjetivo no projeto. Foram adotadas as seguintes técnicas:

- Análise de aplicativos similares;

- Questionário direcionado à comunidade acadêmica;

- Value Proposition Canvas (VPC);

- Redes semânticas.

\subsection{Análise de aplicativos similares}

A análise de produtos similares é uma atividade de benchmark que permite o aprendizado a partir de qualidades de produtos dos concorrentes, identificando aquelas características que podem ser adotadas, evitadas ou superadas (BOGAN e ENGLISH, 1994). Foram selecionados diversos aplicativos de sistemas operacionais 
variados (Android e iOS), e tabulados com a técnica PNI (BONO, 1997), que permite mapear os pontos negativos, positivos e interessantes de cada produto (Quadro 1).

Quadro 1 - Análise de aplicativos de caronas.

\begin{tabular}{|c|l|l|l|}
\hline Aplicativo & \multicolumn{1}{|c|}{ Positivos } & \multicolumn{1}{c|}{ Negativos } & \multicolumn{1}{c|}{ Interessantes } \\
\hline BlaBlaCar (iOS) & $\begin{array}{l}\text { Estética consistente na } \\
\text { interface, muito intuitivo, } \\
\text { transparece segurança, os } \\
\text { tutoriais sugerem usos mais } \\
\text { eficientes do serviço. }\end{array}$ & $\begin{array}{l}\text { As caronas são cobradas, o } \\
\text { aplicativo sugere um valor } \\
\text { mediano e se o usuário quiser } \\
\text { alterar ele indica publicamente se } \\
\text { o valor está alto ou baixo. }\end{array}$ & $\begin{array}{l}\text { Opção de alerta por e-mail (por se } \\
\text { tratar de viagens com prazo } \\
\text { maior), opção de adicionar pontos } \\
\text { no meio do caminho. }\end{array}$ \\
\hline Tripda (iOS/Android) & $\begin{array}{l}\text { Estética consistente. Todas as } \\
\text { opções com fácil acesso. }\end{array}$ & $\begin{array}{l}\text { Busca os locais de ida e partida, } \\
\text { em vez de ir complementando a } \\
\text { busca na própria barra. }\end{array}$ & $\begin{array}{l}\text { Apesar de estilo em que foi } \\
\text { executado, o ícone se diferencia } \\
\text { dos demais. Site promocional } \\
\text { pode servir de inspiração. }\end{array}$ \\
\hline Zaznu (iOS) & $\begin{array}{l}\text { Excelente abordagem visual na } \\
\text { landing page. } \\
\text { Estética das telas, com } \\
\text { harmonia e padronização } \\
\text { gráfica. }\end{array}$ & $\begin{array}{l}\text { Mascote tem bom acabamento } \\
\text { visual, mas não transmite } \\
\text { segurança à figura do motorista. }\end{array}$ & $\begin{array}{l}\text { Apresentação comercial do } \\
\text { produto, principalmente na } \\
\text { landing page. }\end{array}$ \\
\hline
\end{tabular}

Fonte: Elaboração dos autores

\subsection{Questionário}

Foi elaborado um questionário direcionado a toda a comunidade acadêmica (discentes, docentes, técnico-administrativos) interessados em um serviço de caronas, a fim de obter insumos relacionados às suas percepções, experiências e expectativas quanto ao tema. $\mathrm{O}$ instrumento foi disponibilizado eletronicamente nas redes sociais oficiais do setor de tecnologia da informação, atingindo em poucos dias índice expressivo de visualizações orgânicas, compartilhamentos e de respondentes ( $n=735$ ), demonstrando a relevância do assunto para a comunidade. Alguns participaram enviando sugestões nos comentários da publicação on-line.

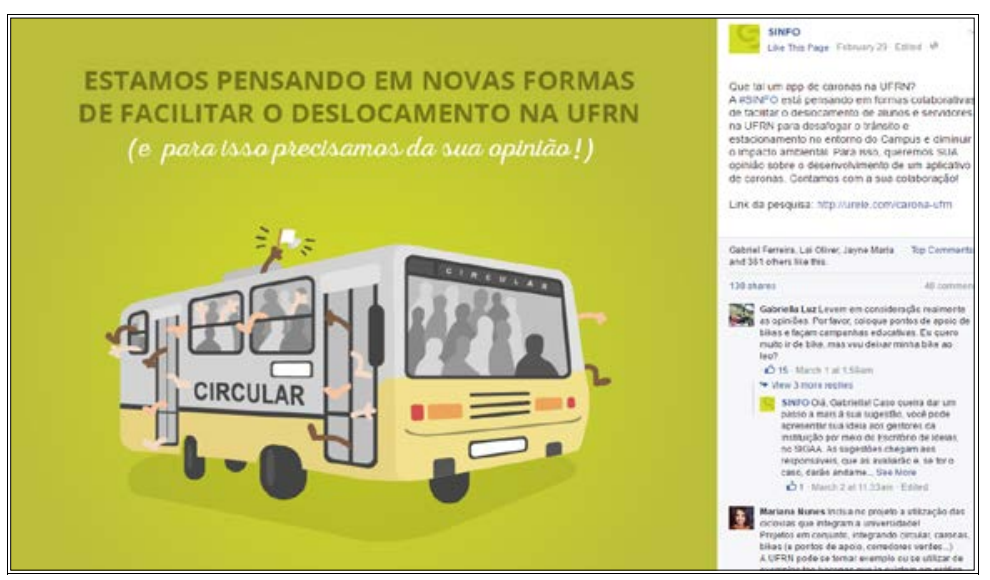

Figura 2 - Questionário divulgado nas redes sociais.

(Fonte: Arquivo dos autores)

O maior estrato de respondentes foi o público de alunos graduandos da instituição (87,9\%, cf. Figura 3), seguidos dos estudantes de pós-graduação $(6,9 \%)$. Participaram também os servidores técnico-administrativos (3,3\%) e docentes (1,9\%). 


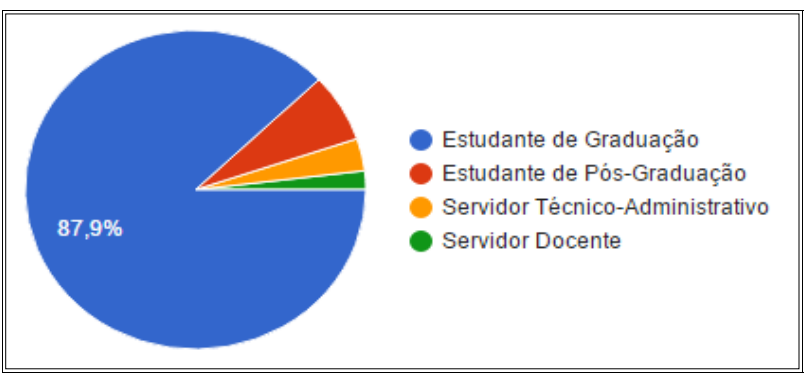

Figura 3 - Grupos que participaram da pesquisa (Fonte: Dados da pesquisa)

Em relação ao gênero dos participantes (Figura 4), houve predominância de respondentes do sexo masculino $(58,6 \%, n=431)$.

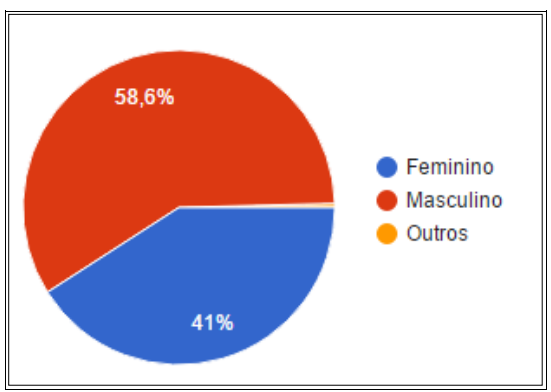

Figura 4 - Gênero dos participantes.

(Fonte: Dados da pesquisa)

Quanto à disponibilidade em oferecer caronas a outras pessoas no campus (Figura 5), 27\% ( $n=199)$ afirmaram já ter oferecido. Dos que afirmaram ter recebido caronas totalizam-se $55 \%(n=404)$.

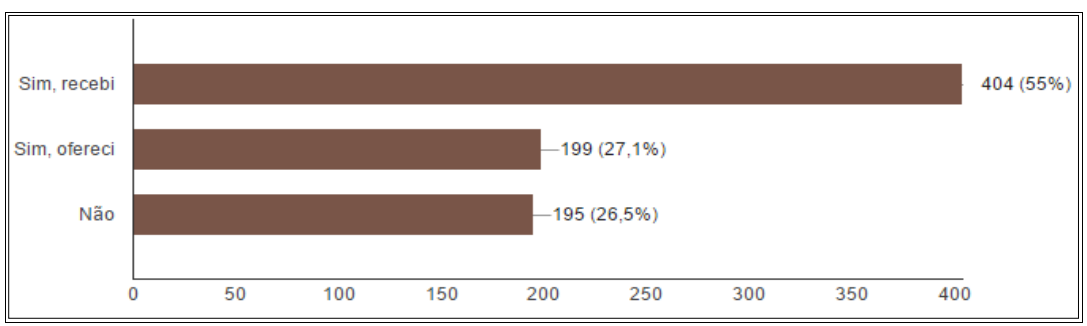

Figura 5. Disponibilidade em oferecer e ter recebido caronas no campus. (Fonte: Dados da pesquisa)

Quando perguntados sobre o tipo de trajeto o qual gostariam de receber caronas (Figura 6), a maioria respondentes (69,5\%) afirmaram estar interessados em deslocamentos do campus para suas imediações mais próximas. Uma parcela de $31,6 \%$ demonstrou interesse em deslocamentos dentro do campus, e uma parcela equiparável (30,5\%) afirmou buscar caronas para deslocamentos do campus para pontos de referência da cidade (shopping center, comércio local, entre outros). 


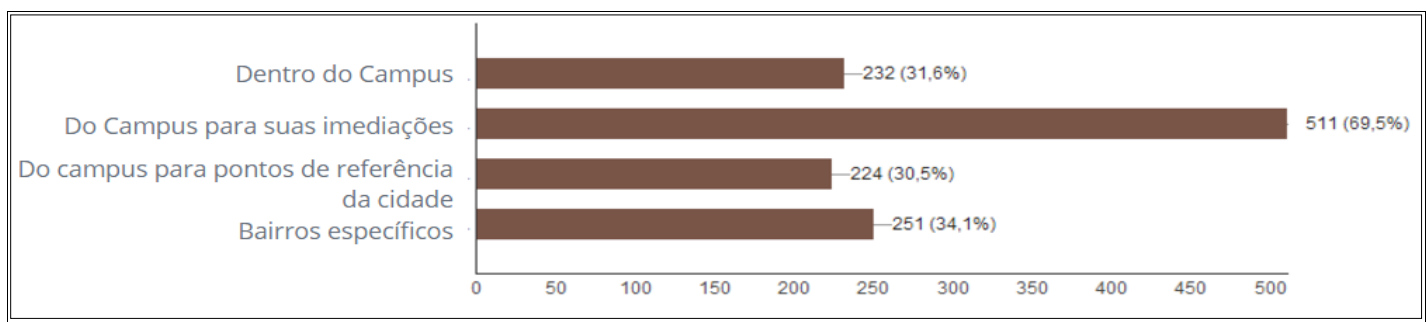

Figura 6 - Tipos de trajeto procurados.

(Fonte: Dados da pesquisa)

A Figura 7 apresenta os principais aspectos esperados em uma carona, no ponto de vista dos que procuram e daqueles que a oferecem.

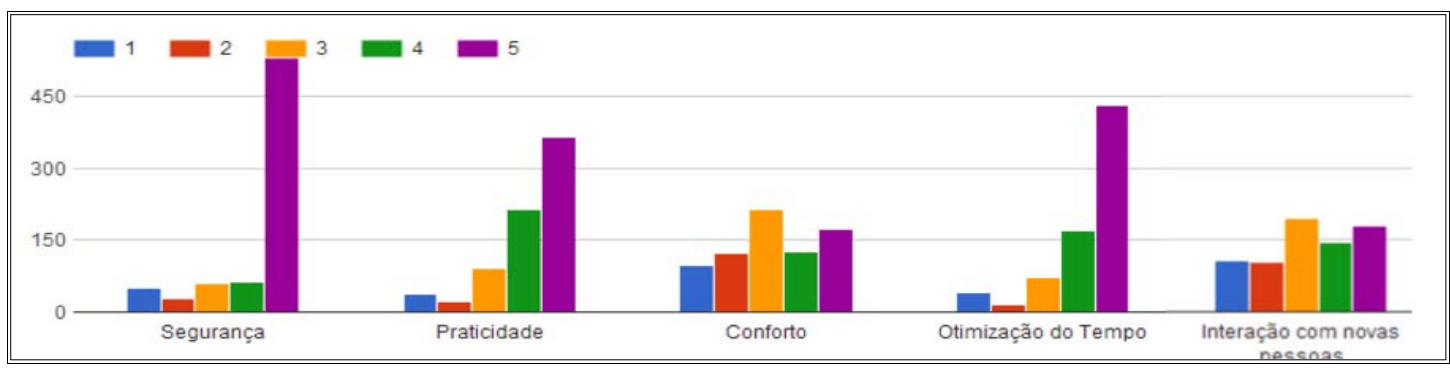

Figura 7 - Aspectos esperados em uma carona.

(Fonte: Dados da pesquisa)

Em escala crescente de importância, foram assinalados índices mais prioritários para os aspectos "segurança" (72,5\%) e "otimização do tempo" (58,9\%).

\subsection{Definição da proposta de valor do aplicativo}

A partir dos dados coletados, as percepções dos sujeitos foram sintetizadas em um quadro de proposta de valor do produto, conhecido como Value Proposition Canvas (VPC) (OSTERWALDER et al., 2015). O VPC é uma derivação de um sistema visual mais amplo de modelagem de negócios, bastante popularizado nas organizações nos últimos anos, chamado Business Model Canvas (BMC), desenvolvido pelo pesquisador e consultor Alexander Osterwalder (2010) e que contém diversos atributos referentes ao planejamento do produto ou organização, como fontes de receita, parceiros, fornecedores, dentre outros. (Figura 8)

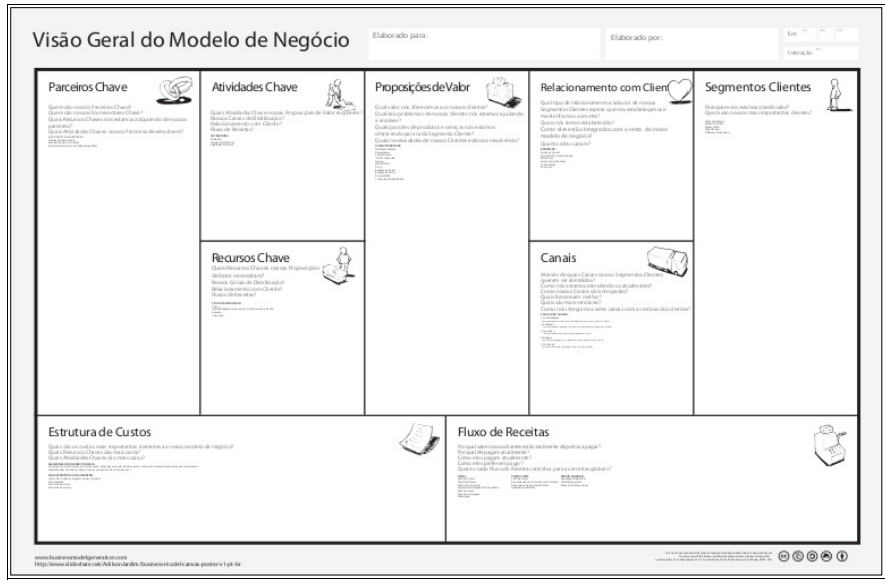

Figura 8 - Business Model Canvas.

(Fonte: Osterwalder, 2010) 
O VPC, por sua vez, é focado em dois aspectos contidos no BMC: o segmento de clientes e a proposta de valor do produto (Figura 9).

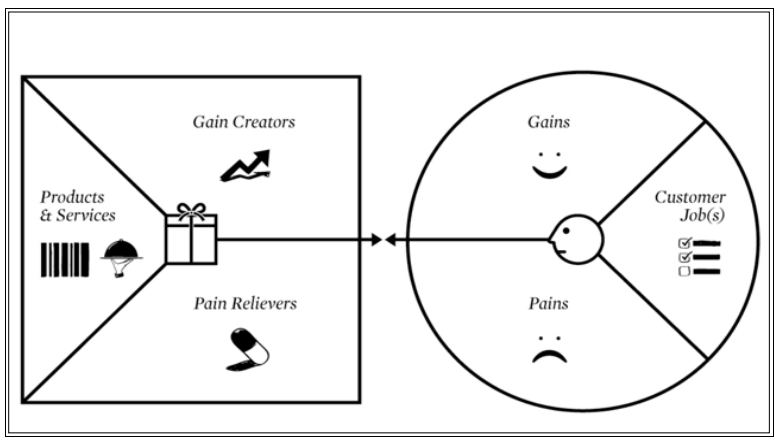

Figura 9 - Modelo de VPC.

(Fonte: Osterwalder et al., 2015)

As duas dimensões do VPC, produto e cliente, são confrontadas, de modo que a equipe de planejamento possa reunir correspondências entre os atributos de ambos. No lado direito, a dimensão do cliente reúne as tarefas ou demandas que o público precisa realizar. Dessas demandas, os clientes esperam atingir ganhos ou benefícios, porém podem encontrar dificuldades ou frustrações ao tentar desempenhá-las. Nesse sentido, o produto vem como resposta às necessidades do cliente, oferecendo funcionalidades, geradores de benefícios e aspectos que atenuem ou eliminem as dores dos clientes (analgésicos). Assim, esta ferramenta foi adotada por permitir um maior grau de empatia com o público-alvo na proposição de soluções, baseando-se nos dados da pesquisa com os potenciais usuários do aplicativo. As opiniões enviadas pelos respondentes (Quadro 2) serviram de base para a elaboração do VPC (Figura 10).

Quadro 2 - Opiniões dos participantes sobre experiência com caronas e sugestões para o aplicativo.

Relatos de experiências

“Excelente, pude chegar mais rápido e com conforto ao destino. E ainda vivenciei uma prática de gentileza que alegra o dia de qualquer um, em troca ficou minha gratidão."

“Estava na parada e um cara que não conheço ofereceu carona para mim e umas amigas minhas. eu aceitei mas as meninas, por questão de segurança, não aceitaram. mas a carona foi tranquila e o cara me deixou na parada do circular no via direta."

"Dei carona para conhecidos da minha turma que moram perto de mim, foi uma experiência tranquila e boa pois conheci melhor as pessoas."

"Geralmente quando algum amigo que tem carro me vê na parada do circular, oferece carona. Fora que no meu bairro muitos amigos também tem carro e eles me oferecem também."
Sugestões para o aplicativo

“Um serviço de carona com identificação, na qual só poderá se cadastrar no aplicativo quem tiver matrícula ativa."

"Para oferecer tais caronas, os usuários do aplicativo têm que ter um cadastro para uso e ser realmente verificado esse cadastro (matricula, foto, etc. Em primeiro lugar vem a segurança de quem pegará a carona."

“Acredito que seria importante uma opção onde as mulheres filtrassem os resultados de carona somente entre mulheres."

"Todas as minhas experiências com carona foram com amigos, por isso ressalto a importância de assegurar de alguma forma a segurança." 


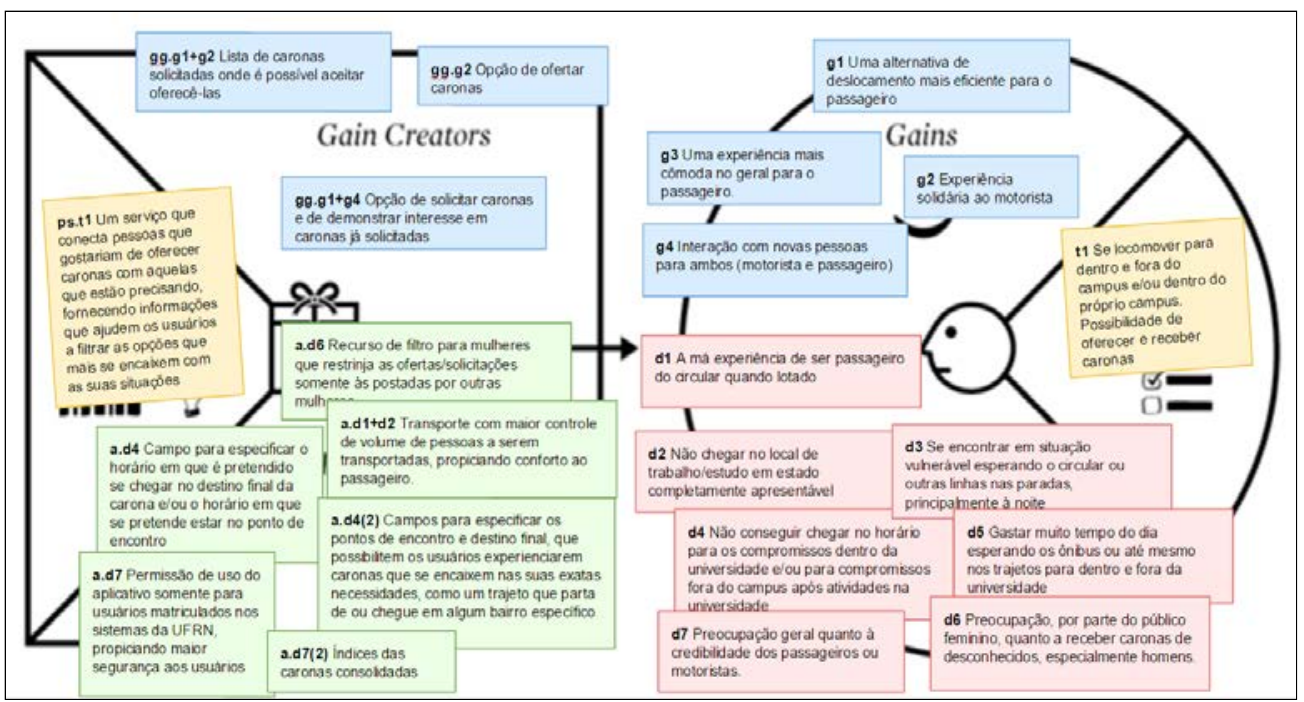

Figura 10 - VPC construído para o aplicativo de caronas.

(Fonte: Elaboração dos autores)

Foi definida uma taxionomia para se referir aos atributos de cada dimensão: ganhos (g), dores (d), tarefas (t), geradores de ganhos (gg), analgésicos (a), produtos e serviços (ps), todos identificados por numerações e diferenciados por cores. Assim, para referir-se a um gerador de ganho para determinado ganho esperado, convencionou-se grafar: gg.g(n). Como mais de um atributo, a sintaxe adotada foi gg.g $\left(n^{\prime}\right)+g\left(n^{\prime \prime}\right)$. Tomando como exemplo, na Figura 10 temos um gerador de ganho do produto para dois ganhos esperados pelo cliente: gg.g1+g2, em que gg="Lista de caronas solicitadas onde é possível aceitar e oferecê-las", g1="Uma alternativa de deslocamento mais eficiente para o passageiro" e g2="Experiência solidária ao motorista". Outro exemplo, mais voltado para a eliminação de problemas (dores), é o "a.d7", em que d7="Preocupação geral quanto à credibilidade dos passageiros ou motoristas", e a="Permissão de uso do aplicativo somente para usuários matriculados nos sistemas da instituição, propiciando maior segurança aos usuários".

\subsection{Redes semânticas}

Após a imersão nas estratégias do produto e percepções do público-alvo, foram reunidos termos-chave a partir das opiniões e definidos os eixos conceituais, ou seja, qualidades responsáveis por direcionar o processo de estruturação e validação do produto. As principais qualidades identificadas para o conceito foram:

- Segurança;

- Empatia;

- Solicitude;

- Coletividade;

- Integração.

Em seguida, foram geradas as associações de palavras e significados (Figuras 11 e 12). 


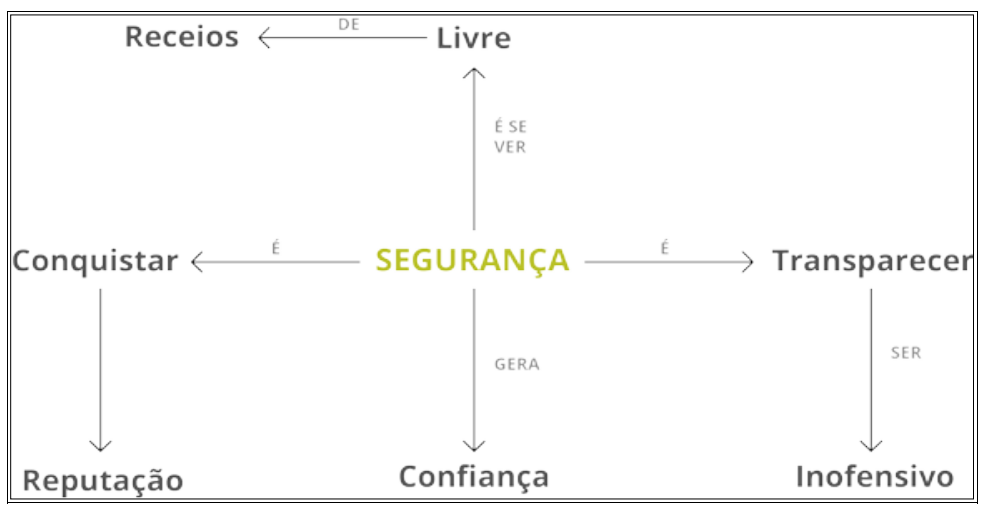

Figura 11 - Rede semântica relativa ao critério "segurança", item considerado relevante pelos respondentes.

(Fonte: Elaboração dos autores)

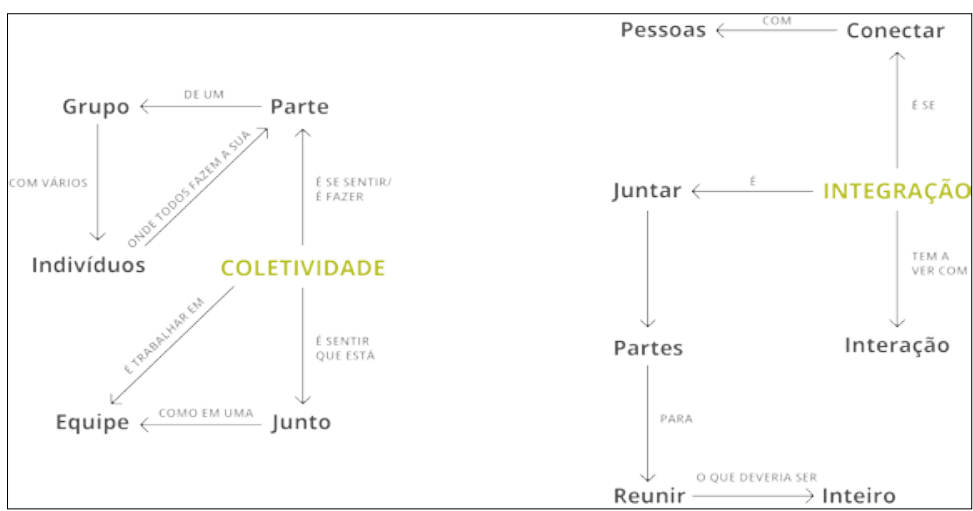

Figura 12 - Rede semântica relativa aos critérios "coletividade" e “integração".

(Fonte: Elaboração dos autores)

A partir das associações, forma elaborados uma variedade nomes para representar os valores conceituais do produto. Foram selecionadas, internamente, duas opções:

- "Até ali": que sugere um gesto prestativo, confiável e ajudador, utilizando uma expressão gentil e despretensiosa;

- "Vem car": que sugere de forma amigável e com linguagem associada a memes da internet, a ideia de coletividade e aproximação.

A escolha dos nomes se deu pela originalidade e pela disponibilidade para registro nas lojas de aplicativos móveis. Após o processo criativo, as alternativas foram levadas para validação do público-alvo.

\section{RESULTADOS E DISCUSSÕES}

A validação contou um grupo $(n=78)$ de respondentes do primeiro questionário, que se disponibilizaram para as etapas seguintes da pesquisa. A abordagem foi realizada por meio de questionário eletrônico. Os respondentes escolheram o nome que mais se encaixava com as qualidades conceituais do produto (Figura 13). 


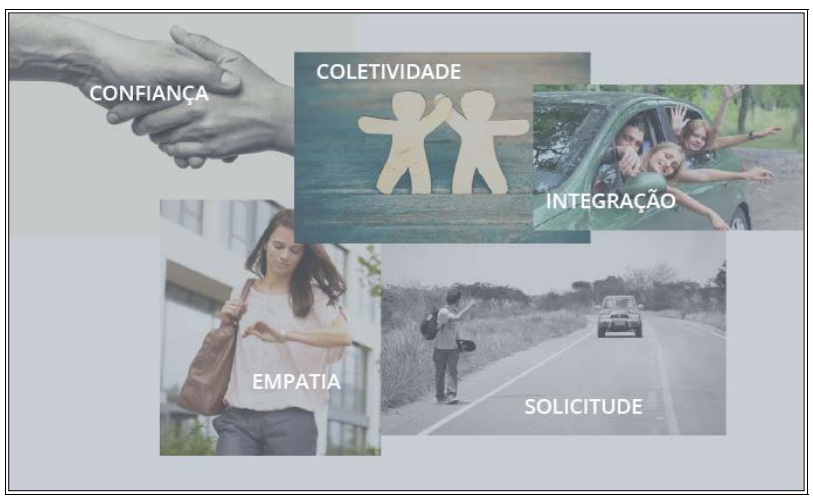

Figura 13 - Painel semântico utilizado pelos respondentes durante a validação dos nomes.

(Fonte: Elaboração dos autores)

De acordo com a opinião dos usuários, o nome mais alinhado ao conceito foi "Vem car", com 54,5\% da preferência dos respondentes (Figura 14).

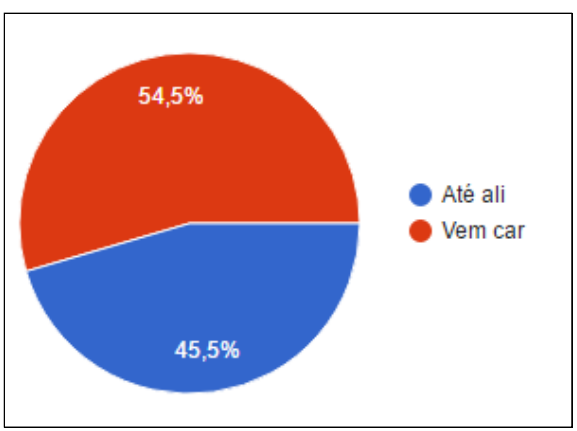

Figura 14 - Validação do nome pelos usuários.

(Fonte: Elaboração dos autores)

Após a escolha do nome pelo público-alvo, puderam ser desenvolvidas a marca e identidade visual do aplicativo (Figura 15).

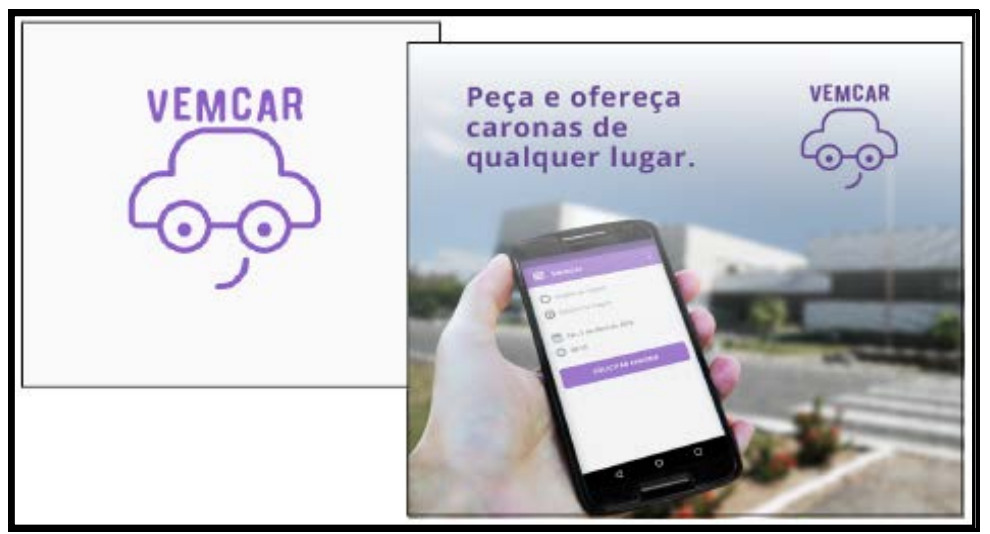

Figura 15 - Marca e identidade visual do aplicativo.

(Fonte: Elaboração dos autores)

\section{CONSIDERAÇÕES FINAIS}

Verificou-se uma proveitosa combinação entre as ferramentas estratégicas de gestão e as técnicas de criatividade adotadas, que permitiram contemplar os critérios de identidade verbal e visual de marca (RODRIGUES, 2011), alicerçando o conceito 
para o design da interface do produto final. A integração da ferramenta Value Proposition Canvas (OSTERWALDER, 2010) ao processo criativo demonstrou profícua interação com os dados qualitativos oriundos das abordagens com os potenciais usuários do produto, permitindo delimitar em quadrantes os dados coletados, servindo portanto como uma ferramenta de tratamento de dados da abordagem com - público-alvo para a síntese dos problemas e insumos coletados. Como desdobramentos futuros, pretende-se observar a eficiência da aplicação do VPC em projetos no âmbito da comunicação organizacional para estratégia de marcas e serviços no meio digital.

\section{REFERÊNCIAS}

API.Sistemas - API de serviços da UFRN. O que é API.Sistemas?. Disponível em: $<$ https://api.ufrn.br/>. Acesso em maio 2016.

ARGAN, G. C. Walter Gropius e a Bauhaus. Rio de Janeiro: José Olympio, 2005.

BOARETO, R. A política de mobilidade urbana e a construção de cidades sustentáveis. Revista dos Transportes Públicos - ANTP, Ano 30/31, p. 143 - 160, 2008.

BOGAN, C. E.; ENGLISH, M. J. Benchmarking for Best Practices: Winning Through Innovative Adaptation. New York: McGraw Hill Education, 1994.

BONO, E. Criatividade levada a sério: como gerar ideias produtivas através do pensamento lateral. São Paulo: Pioneira Editora, 1997.

IIDA, I. Ergonomia: projeto e produção. 2ed. São Paulo: Blucher, 2005.

INTERNATIONAL ORGANIZATION FOR STANDARDIZATION. Ergonomic requirements for office work with visual display terminals (VDTs) - Part 11: Guidance on usability. In:

ISO 9241-11:1998(en). Disponível em: <https://www.iso.org/obp/ui/\#iso:std:iso:9241:11:ed-1:v1:en>. Acesso em maio 2016.

LOWDERMILK, T. Design centrado no usuário: um guia para o desenvolvimento de aplicativos amigáveis. São Paulo: Novatec, 2013.

MAGAGNIN, R. C.; SILVA, A. N. R. A percepção do especialista sobre o tema mobilidade urbana. Revista Transportes, v. XVI, n. 1, p. 25-35, jun/2008.

NIELSEN, J. Heuristic evaluation. In: NIELSEN, J.; MACK, R.L. (Orgs.). Usability

Inspection Methods. New York: John Wiley \& Sons, 1994.

NORMAN, D. A. Design do futuro. Rio de Janeiro, Rocco, 2010.

OSTERWALDER, A.; PIGNEUR, Y. Business model canvas. Self published. 2010.

OSTERWALDER, A.; PIGNEUR, Y.; BERNARDA, G.; SMITH, A. Value Proposition Design: How to Create Products and Services Customers Want. John Wiley \& Sons, 2015.

RESENDE, P. V.; SOUSA, P. R. Mobilidade urbana nas grandes cidades brasileiras: um estudo sobre os impactos do congestionamento. Nova Lima - MG: Fundação Dom Cabral, 2009.

RODRIGUES, D. Naming: o nome da marca. Rio de Janeiro: 2AB, 2011.

SANTAELLA, L. Semiótica aplicada. São Paulo: Pioneira Thomson Learning, 2005 
SHNEIDERMAN, B.; PLAISANT, C. Designing the User Interface: Strategies for Effective Human-Computer Interaction. New Jersey: Pearson Education, 1986.

QUEIROZ, A. H. Empatia e Inovação: Uma proposta de metodologia para concepção de novos produtos. 1999. Tese de Doutorado. Universidade Federal de Santa Catarina, Centro Tecnológico. 